\title{
Review of Bone Substitutes
}

\author{
Landon S. Pryor, M.D., ${ }^{1}$ Earl Gage, M.D.,' ${ }^{1}$ Claude-Jean Langevin, M.D., ${ }^{1}$ \\ Fernando Herrera, M.D., ${ }^{2}$ Andrew D. Breithaupt, B.A., ${ }^{2}$ Chad R. Gordon, D.0., ${ }^{1}$ \\ Ahmed M. Afifi, M.D.,' James E. Zins, M.D., ${ }^{1}$ Hal Meltzer, M.D., 3 \\ Amanda Gosman, M.D., ${ }^{2}$ Steve R. Cohen, M.D., ${ }^{3}$ and Ralph Holmes, M.D. ${ }^{3}$
}

\begin{abstract}
Bone substitutes are being increasingly used in craniofacial surgery and craniomaxillofacial trauma. We will review the history of the biomaterials and describe the ideal characteristics of bone substitutes, with a specific emphasis on craniofacial reconstruction. Some of the most commonly used bone substitutes are discussed in more depth, such as calcium phosphate and hydroxyapatite ceramics and cements, bioactive glass, and polymer products. Areas of active research and future directions include tissue engineering, with an increasing emphasis on bioactivity of the implant.
\end{abstract}

KEYWORDS: Bone substitutes, biomaterials, calcium phosphate cements, hydroxyapatite, polymethylmethacrylate, porous polyethylene

Bone substitutes are being increasingly used in craniofacial surgery. This is due to their ease of use and handling, improved safety profiles, intraoperative cost and time advantages, and adaptability to a variety of clinical challenges. A wide variety of bone substitutes have been employed over the past 50 years, as shown in Table 1. Biomaterials used in the osseous reconstruction of the craniofacial skeleton can be broadly categorized into calcium phosphate-based ceramics and cements, synthetic polymers, and, most recently, tissue-engineered bone substitutes. We will review some of the most important biomaterials in each of these categories.

The art of repairing a bone defect has been accomplished and refined by man for thousands of years. Excavations of a Neolithic era Peruvian tribal chief revealed a frontal bone defect repaired with a hammerapplied gold plate. ${ }^{1}$ Examination of a skull from 2000 $\mathrm{BC}$ uncovered evidence of healing around a 7-mm defect repaired with a piece of animal bone. ${ }^{2}$ The Egyptians practiced some extremely advanced orthopedic procedures for the time. Anthropologists have studied the mummy of a priest who had a $23-\mathrm{cm}$ prosthesis inserted at the left knee. Examination of the device revealed that it had been made of pure iron and cemented with resin, and it was inserted while the priest was still alive. ${ }^{3}$

Surgeon Job van Meekeren heralded the modern era of bone replacement in 1668 when he successfully performed the first heterologous graft by inserting the fragment of a dog skull into the skull of an injured soldier. ${ }^{4}$ Because of the blasphemous nature of the operation, the soldier was excommunicated from the church. When he went to von Meekeren to have the graft removed, it had already become fully incorporated into his skull. In 1820, a Germany surgeon by the name of Philips von Walter performed the first autologous graft, replacing a cranium fragment after trepanation. ${ }^{5}$

Although autologous bone grafting is still considered the "gold standard" in bony defect repair, the past century has seen significant advances in alternatives to natural bone. A bone substitute can be defined as "a synthetic, inorganic or biologically organic combination which can be inserted for the treatment of a bone defect
${ }^{1}$ Department of Plastic Surgery, Cleveland Clinic Foundation, Cleveland, Ohio; ${ }^{2}$ Division of Plastic Surgery, University of California San Diego, San Diego, California; ${ }^{3}$ Rady Children's Hospital, San Diego, California.

Address for correspondence and reprint requests: Landon S. Pryor, M.D., Aesthetic Fellow, Department of Plastic Surgery, Cleveland Clinic Foundation, Crile Building A60, 9500 Euclid Avenue,
Cleveland, OH 44195 (e-mail: pryorl2@ccf.org).

Craniomaxillofac Trauma Reconstruction 2009;2:151-160. Copyright (C) 2009 by Thieme Medical Publishers, Inc., 333 Seventh Avenue, New York, NY 10001, USA. Tel: +1(212) 584-4662.

Published online: June 2, 2009.

DOI 10.1055/s-0029-1224777. ISSN 1943-3875. 
Table 1 Commonly Used Calcium-Based and Polymer Bone Substitutes

\begin{tabular}{|c|c|}
\hline Compound & $\begin{array}{l}\text { Sample of Commercial } \\
\text { Products }\end{array}$ \\
\hline Hydroxyapatite & $\begin{array}{l}\text { Pro-Osteon, Bio-Oss, Endobon, } \\
\text { Calcitite }\end{array}$ \\
\hline Tricalcium phosphate & Vitoss \\
\hline Hydroxyapatite cements & $\begin{array}{c}\text { Norian CRS, Bone Source, } \\
\text { Mimix Bone Void Filler }\end{array}$ \\
\hline Bioactive glass & NovaBone \\
\hline Methylmethacrylate polymer & Hard Tissue Replacement \\
\hline Porous polyethylene polymer & Medpor \\
\hline
\end{tabular}

instead of autogenous or allogenous bone." ${ }^{6}$ The first reported modern use of a bone substitute took place in 1892 when Dressmann used calcium sulfate, or plaster of Paris, to fill bony defects. ${ }^{7}$

Methylmethacrylate, an acrylic resin, was first introduced in the 1940s and remains a popular choice as a bone substitute. It has more recently been combined with various metallic meshes to facilitate fixation and provide additional strength. The latter half of the 20th century has seen the evolution of the hydroxyapatite and calcium phosphate-based cements and ceramics. Current advances are being made with the development of tissueengineered products, incorporating growth factors and stem cells.

The ideal bone substitute must have several important properties. It must be biocompatible with the host and not evoke an adverse inflammatory response. It should be able to be easily molded to a bony defect with a practical time to set. Durability of the implant is important so that it maintains its shape and volume over time. Radiolucency is ideal to allow for optimal radiographic assessment. Finally, the ideal bone substitute should also be thermally nonconductive, bioactive, able to be sterilized, and readily available, at a reasonable cost to purchase and use.

Hydroxyapatite $\left[\mathrm{Ca}_{10}\left(\mathrm{PO}_{4}\right)_{6}(\mathrm{OH})_{2}\right](\mathrm{HA})$ is a calcium phosphate compound that is the primary mineral component of teeth and bone. For the past 30 years, it has been popular in craniofacial and orthognathic surgery, filling bony defects and smoothing contour irregularities. HA ceramics come in both naturally occurring and synthetic forms. Clinically available, naturally occurring forms of $\mathrm{HA}$ include the coral-based products Interpore and Pro-osteon (Interpore International, Inc., Irvine, CA) as well as bovine derived products such as Bio-Oss (Geistlich Biomaterials, Geistlich, Switzerland), Osteograf-N (CeraMed Co., Denver, $\mathrm{CO}$ ), and Endobon (Merck Co., Darmstadt, Germany). The synthetic HA product is Calcitite (Sulzer Calcitek, Carlsbad, CA). HA ceramics are manufactured in a variety of forms including granules and porous blocks (Fig. 1). HA is also frequently used as a coating on orthopedic and dental implants to promote bony ingrowth. ${ }^{8}$

Although HA accounts for nearly $70 \%$ of the mineral content of teeth and bone, the naturally occurring HA in the human body exists in a substituted form. Carbonate and silicates, among other ions, may replace hydroxyl or phosphate groups of the apatite structure. Investigators have attempted to produce carbonate- and silicon-substituted synthetic HA in an effort to produce HA that more closely resembles the mineral content of native bone, enhancing bioactivity and osteoconduction. $^{9}$ Although there are few of products in clinical use at this time, HA substitution will likely remain an active area of research.

Tricalcium phosphate $\left[\mathrm{Ca}_{3}\left(\mathrm{PO}_{4}\right)_{2}\right](\mathrm{TCP})$ is a synthetic compound created by sintering precipitated calcium-deficient apatite with calcium phosphate in a ratio of 1:5. TCP is more soluble than $\mathrm{HA}$ due to its small granule size and porosity. A pure TCP product is commercially available as Vitoss (Orthovita, Inc., Philadelphia, PA). This product is engineered to resemble cancellous bone and is used to fill traumatic cancellous bone defects. This product has more limited applications in craniofacial reconstruction (Fig. 2), but many other calcium phosphate and HA cement products are more widely used.

Since the early 1990s, calcium phosphate cements have become one of the most versatile bone substitutes, filling calvarial defects and smoothing contour abnormalities of the facial skeleton. These calcium phosphate-based cements do not have sufficient tensile and compressive strength to be used in load-bearing applications, but their ability to be precisely sculpted has made them extremely useful. A comparison of the three most commonly used HA cements is summarized in Table 2.

Norian CRS Bone Cement (Synthes, Paoli, PA) is a pliable calcium phosphate cement that is mixed in vivo to form dahllite, a carbonated apatite, once set. Originally approved by the Food and Drug Administration (FDA) for use in distal radius fractures ${ }^{10}$ it has found broad application in craniofacial surgery. Norian CRS bone cement is prepared by mixing sodium phosphate solution with calcium powder to form a bone putty. This putty begins to harden in 2 minutes during an exothermic reaction that may reach as high as $42^{\circ} \mathrm{C}$ and is set in 10 minutes. Maximum strength is not achieved until 24 hours. ${ }^{10}$ In a recent study of Norian by Zins et al, reconstructed skull bone defects in sheep showed excellent osteointegration but almost no osteoconductivity over the course of 12 months. ${ }^{11}$ Drop-tests resulted in fractures of in the center of the construct rather than at the bone-cement interface. Norian is slowly absorbed over time and is not intended for use in load-bearing areas or in the presence of active infection. 

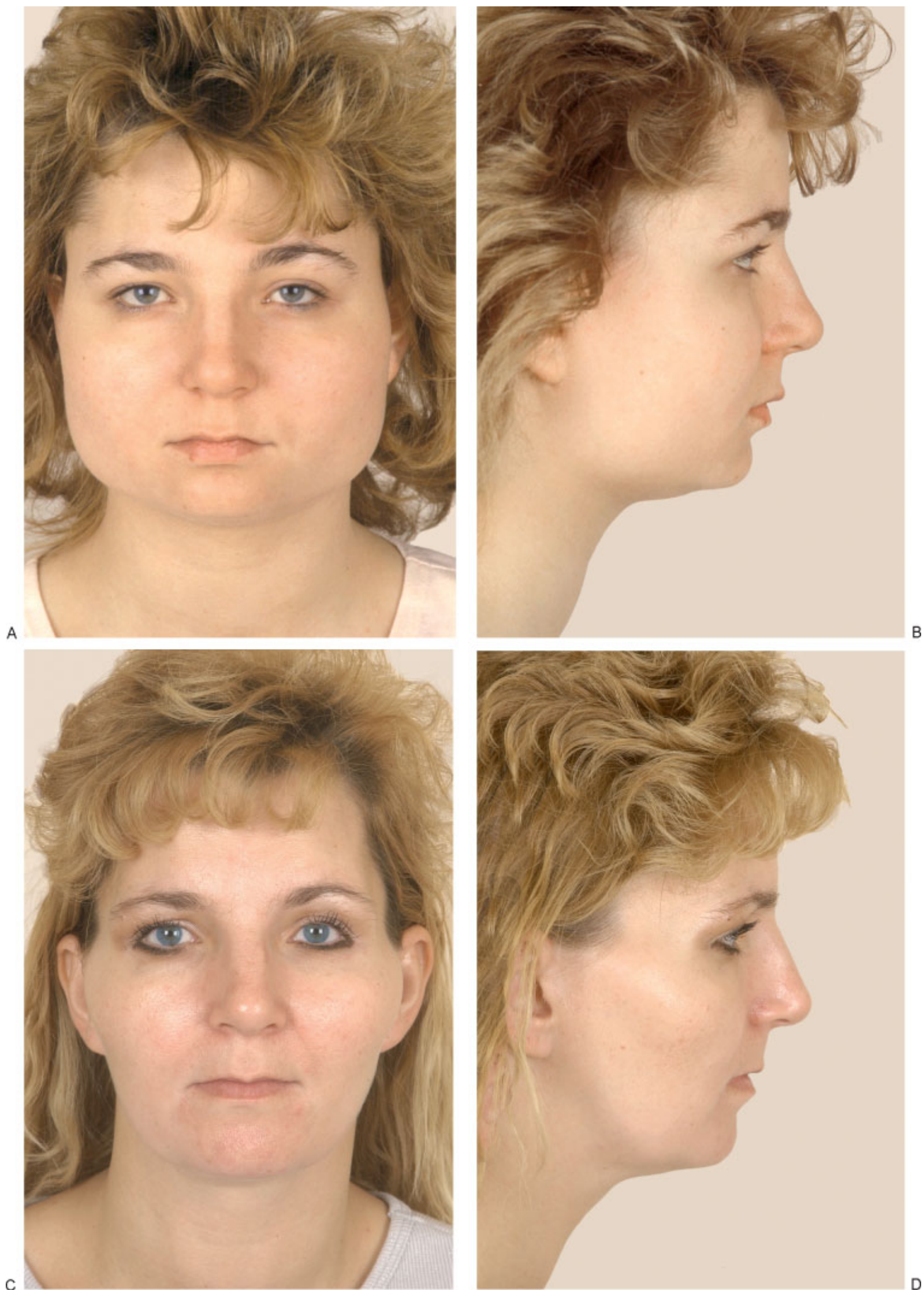

Figure 1 (A and B) Masseteric hypertrophy and vertical microgenia. Correction was performed by gonial angle resection bilaterally and vertical lengthening genioplasty using block hydroxyapatite. Front and profile views after surgery. (C and D) Frontal and profile views 8 years later. 


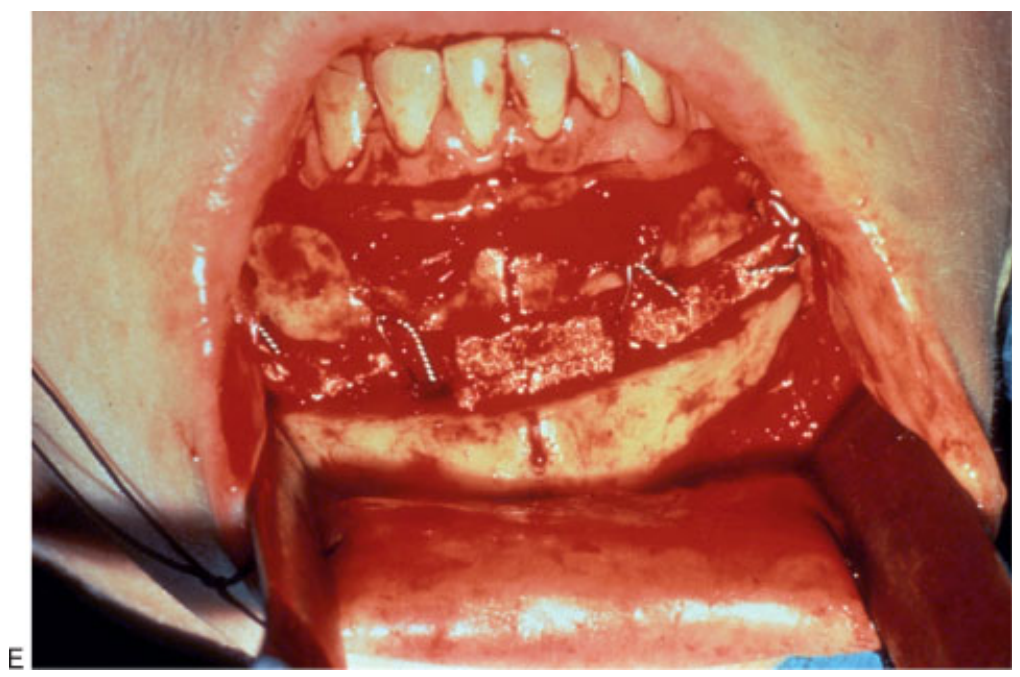

Figure 1 (Continued) (E) Intraoperative view of vertical lengthening genioplasty using block hydroxyapatite. (Reprinted with permission from Zins JE, et al. Contour alteration of the facial skeleton. In: Achauer BM, Guyuron B, eds. Plastic Surgery: Indications, Operatons, Outcomes. Philadelphia: Elsevier; 2000:2824. Copyright Elsevier 2000.)

Bone Source (Stryker-Leibinger, Kalamazoo, MI) is a self-setting calcium phosphate cement originally approved for use in filling burr holes and for facial skeleton augmentation ${ }^{12}$ (Fig. 3). It is prepared by mixing calcium phosphate salts in a sodium phosphate buffer, forming a bone putty that remains malleable for approximately 20 minutes. Bone Source hardens into HA, and like other HA cements, is very slowly absorbed over time. It is not intended to fill defects over $25 \mathrm{~cm}^{2}$ and lacks sufficient strength for load-bearing applications.

Mimix Bone Void Filler (W. Lorenz Surgical, Jacksonville, FL), like Bone Source, achieved FDA approval for use in filling burr hole and craniotomy defects and in smoothing facial skeletal contour abnormalities over a surface area of no larger than $25 \mathrm{~cm}^{2} .{ }^{13}$ This cement product is prepared by mixing dry components of calcium phosphate powder and sodium citrate dehydrate with an anhydrous citric acid solution. As it cures, Mimix hardens into HA and is mildly exothermic. Mimix Quickset is rapidly prepared, remains malleable for 3 to 4 minutes, and is completely set in 4 to 6 minutes, offering a potential advantage over other commercially available HA cement products that take longer to set and cure. ${ }^{14}$

Since the introduction of HA cements, they have found broad use and application in craniofacial defects. The largest review of HA cements in craniofacial reconstruction was published by Burstein and colleagues. ${ }^{15}$ They reviewed 150 patients who underwent orbitocranial reconstruction using Bone Source and Mimix HA cements over 7 years. The majority of patients were reconstructed with an onlay technique, with or without adjunctive absorbable or titanium mesh. Excellent results were reported, with $92 \%$ of patients having a satisfactory result over a minimum of 1-year follow-up. The overall complication rate was $9 \%$ but no infections were reported.
Other series have reported much higher rates of infection/exposure ${ }^{16-20}$ Moreira-Gonzalez et al found that infection or extrusion occurred in $22.4 \%$, with an increased risk for infection in the vicinity of the frontal sinus. ${ }^{19}$ This finding has also been corroborated by Verret et al. $^{18}$ In their review of 102 patients undergoing craniofacial reconstruction for traumatic and malignancy-related defects, they reported a $12 \%$ incidence of infection/foreign body reaction requiring implant removal. Tissue irradiation and frontal sinus involvement both increased the risk for these complications. Microfragmentation has also been reported as a complication of HA cement. ${ }^{15,16,20,21}$ Losee et al attribute microfragmentation to brain pulsations in cranial reconstruction and suggest that this risk can be mitigated in large defects by including mesh as an adjunct to cement. ${ }^{21}$ Combined use of both titanium and absorbable mesh products with HA cements has been shown to be safe and effective by several authors. ${ }^{21-23}$ Choice of HA cement may also affect the rate of microfragmentation, with Norian having recently demonstrated the highest mean fracture force required to fracture a standardized test piece. ${ }^{22}$ Zins et al reviewed 121 patients undergoing craniofacial reconstructions using Norian and Bone Source with and without mesh adjuncts and found an overall major complication rate of $15 \% .{ }^{20}$ However, in a subset of patients undergoing reconstructions for large $\left(>25 \mathrm{~cm}^{2}\right)$ defects, major complications occurred in $63 \%$ of patients (Fig. 4). As a result of these findings, Zins recommends autogenous reconstruction for large cranial defects, even if mesh is utilized.

Bioactive glass is a synthetic, osteoconductive, silica-containing particulate bone filler that forms an osteoconductive apatite layer at the bone-implant interface. This enhances bone attachment and promotes new bone growth. ${ }^{24}$ Collagen, mucopolysaccharides, 

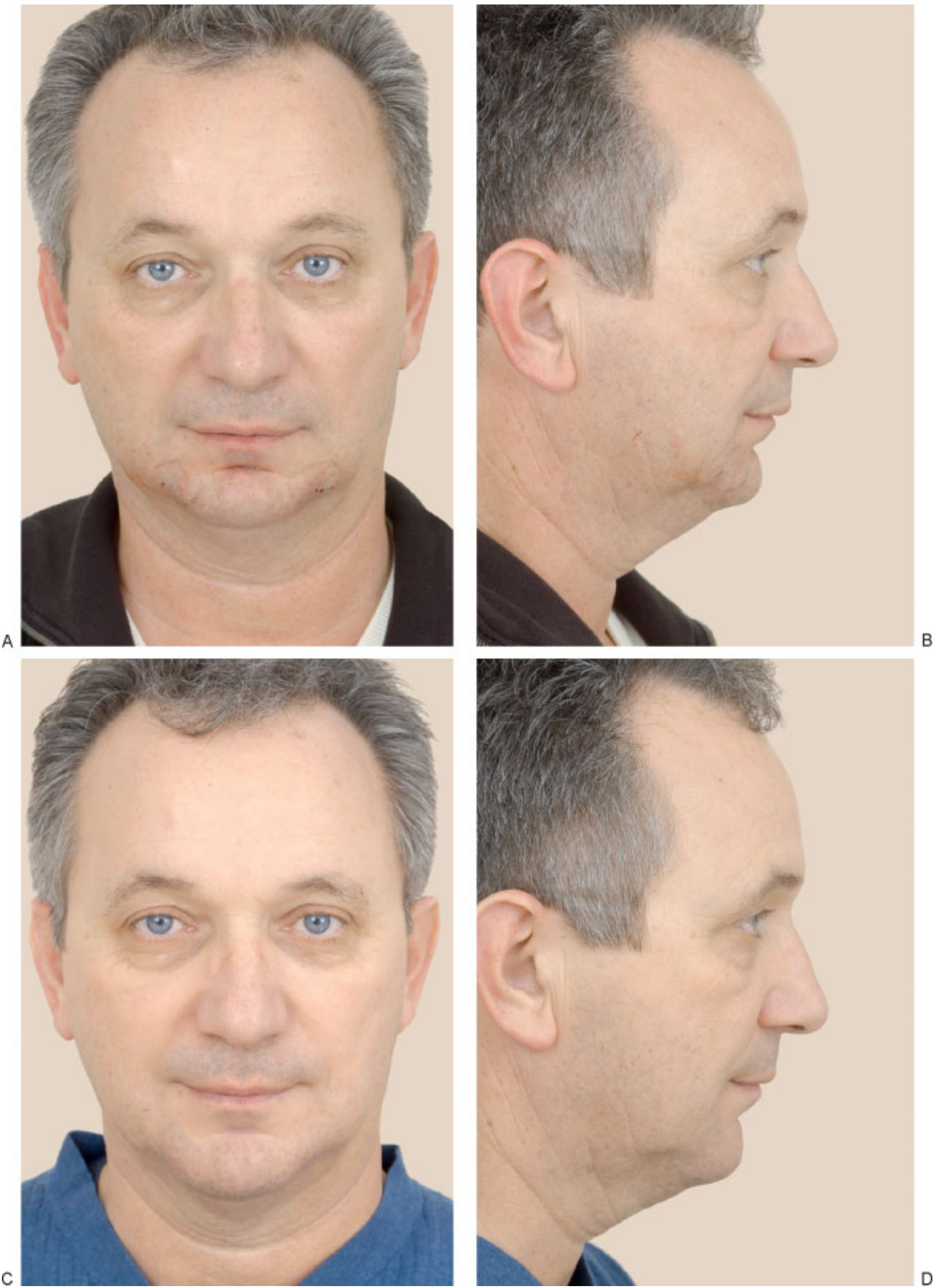

Figure 2 (A and B) A 55-year-old man who presented with a decrease in his lower vertical facial height due to vertical microgenia. Postoperative (C) frontal and (D) profile views following vertical lengthening genioplasty and interposition implant of tricalcium phosphate. (Reprinted with permission from Zins JE. Aesthetic surgery of the aging face and neck. In: Siemionow M, Eisenmann-Klein M, eds. Plastic and Reconstructive Surgery Series. Berlin: Springer; 2009:Figure 26.4.) 
Table 2 Comparison of the Properties of Calcium Phosphate Cements

\begin{tabular}{|c|c|c|c|}
\hline & Norian & Bone Source & Mimix \\
\hline Base component & $\begin{array}{c}\text { Monocalcium phosphate, tricalcium } \\
\text { phosphate, calcium carbonate }\end{array}$ & Tetracalcium phosphate & $\begin{array}{l}\text { Tetra-tri-calcium } \\
\text { phosphate }\end{array}$ \\
\hline Compression strength (psi) & 4350 & 7396 & 3300 \\
\hline Resorbability & Complete & Minimal & Minimal \\
\hline Pore diameter ( $\mu \mathrm{m})$ & 0.03 & $0.002-0.005$ & 211 \\
\hline Final set time & $1 \mathrm{~h}$ & $4 \mathrm{~h}$ & $4-6 \min$ \\
\hline Sets in a moist environment & Yes & No & Yes \\
\hline Osteoconductive & Yes & Yes & Yes \\
\hline
\end{tabular}

and glycoproteins are recruited from the adjacent bone, facilitating early bonding of the bioactive glass with surrounding bone. Once mature, this bond has been shown to be stronger than the native bone itself. Fracturing is more likely to occur within the native bone or the bioglass substance rather than at the interface between them. ${ }^{24,25}$ In addition to its osteoconductive properties, bioactive glass has also been reported to be osteoinductive. The bioactive surface becomes coated with osteogenic stem cells in response to the controlled release of soluble silicon from the glass surface. $^{26,27}$

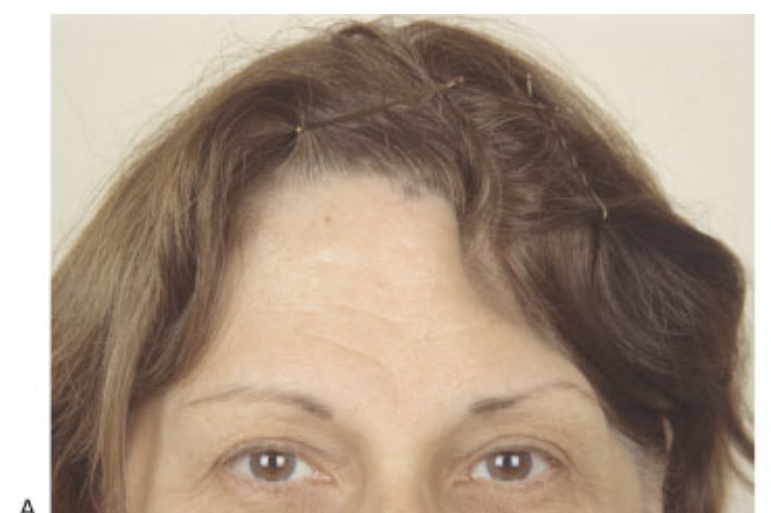

A

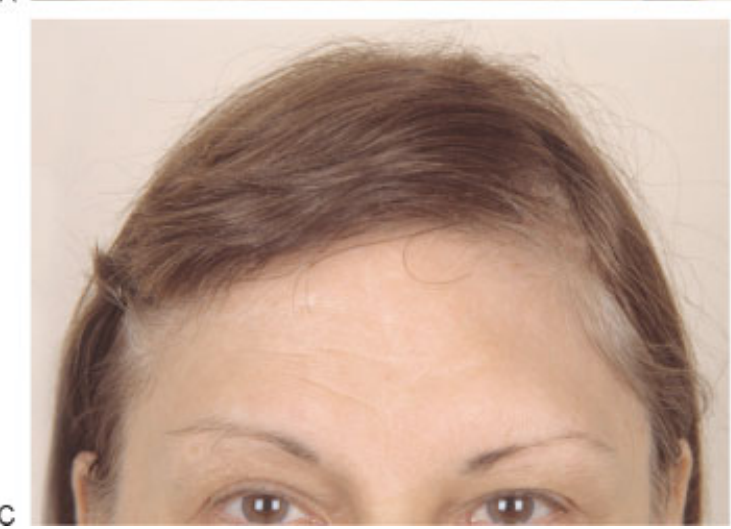

NovaBone (Porex Surgical, College Park, GA) is a commercially available bioactive glass intended for filling surgical or traumatic bone gaps. ${ }^{28}$ Its composition is $45 \%$ silica dioxide, $45 \%$ sodium oxide, $5 \%$ calcium, and $5 \%$ phosphate. $^{24}$ NovaBoneAR, a second-generation NovaBone product, has two components: a slowly absorbing, melt-derived calcium phosphosilicate bioglass and a more rapidly absorbed solution-gelation calcium phosphosilicate component. The latter is more rapidly absorbed, leaving more space for bone infiltration in the interstices between the more slowly absorbed meltderived component. NovaBone thus acts as a scaffold
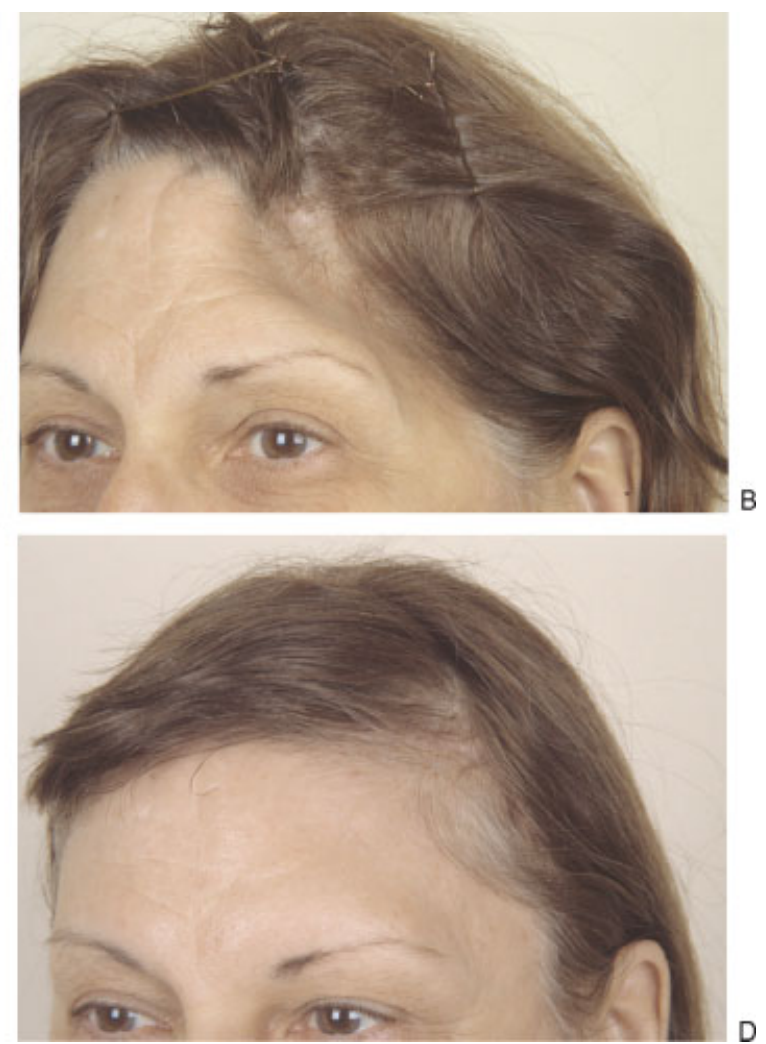

Figure 3 ( $A$ and B) Left frontotemporal defect in 48-year-old woman caused by removal of infected bone flap 2 years earlier. Frontal and three-quarter views shown before surgery. ( $C$ and D) Frontal and three-quarter views 6 months after reconstruction of full-thickness defect with hydroxyapatite bone paste (Bone Source). (Reprinted with permission from Zins JE, et al. Contour alteration of the facial skeleton. In: Achauer BM, Guyuron B, eds. Plastic Surgery: Indications, Operatons, Outcomes. Philadelphia: Elsevier; 2000:2829. Copyright Elsevier 2000.) 
for the ingrowth of new bone and is substantially resorbed within 6 months. NovaBone Putty is similar to NovaBoneAR except that the bioglass particulate material is mixed with a gelatin binding agent to form a malleable putty that can be packed into osseous defects. ${ }^{29}$ The gelatin component will also reabsorb over time, leaving the osteoconductive bioglass matrix to promote bony ingrowth. NovaBone is not intended for heavy load-bearing applications prior to completion of bony ossification.
Cho and Gosain reviewed the role of bioactive glass in craniofacial surgery, describing its use in periodontal, alveolar, orbital floor, maxillofacial, and cranial applications. $^{24,26}$ Bioactive glass has been used in a mixture with autogenous bone particles and demineralized bone matrix, resulting in accelerated bone healing compared with bone grafting alone. ${ }^{26,27,30,31}$ Complication rates from the use of bioactive glass in craniofacial reconstruction have been described as high as $20 \%$ in one series. $^{32}$
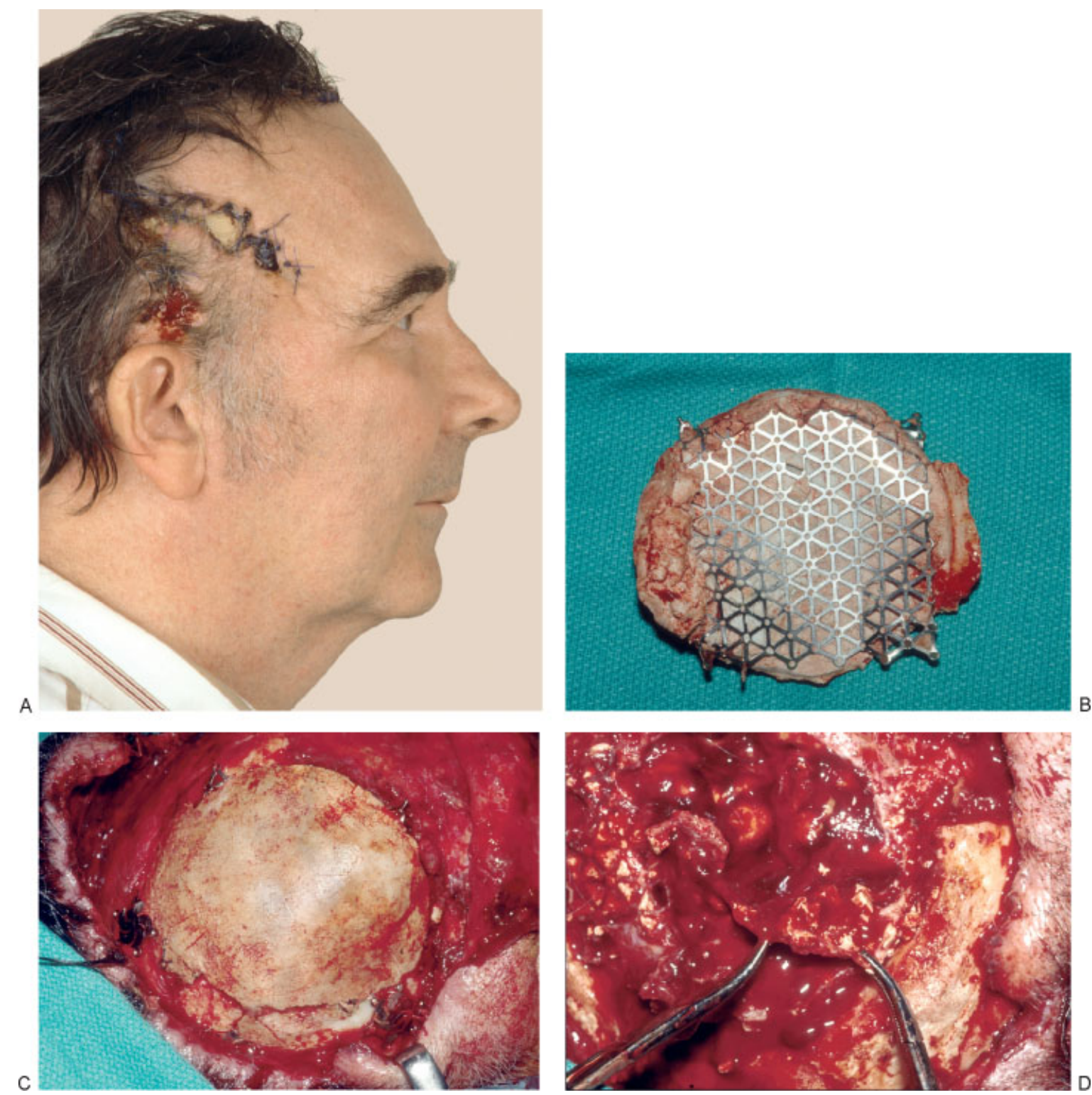

Figure 4 (A) Preoperative view of a 54-year old man who underwent surgery for brain tumor removal and immediate reconstruction with calcium-based bone cement elsewhere. The cement became exposed, and two attempts to close the area using local flaps were performed. The patient was then referred to us for free flap coverage. (B, $C$, and D) The patient underwent reoperation, and all calcium-based bone cement plus the titanium mesh used for reconstruction was removed. Part of the dura had to be excised because it was attached to the calcium-based bone cement. A dural patch was used for reconstruction. Calcium-based bone cement was used to reconstruct a 132-cm² cranial defect 21 months later. 


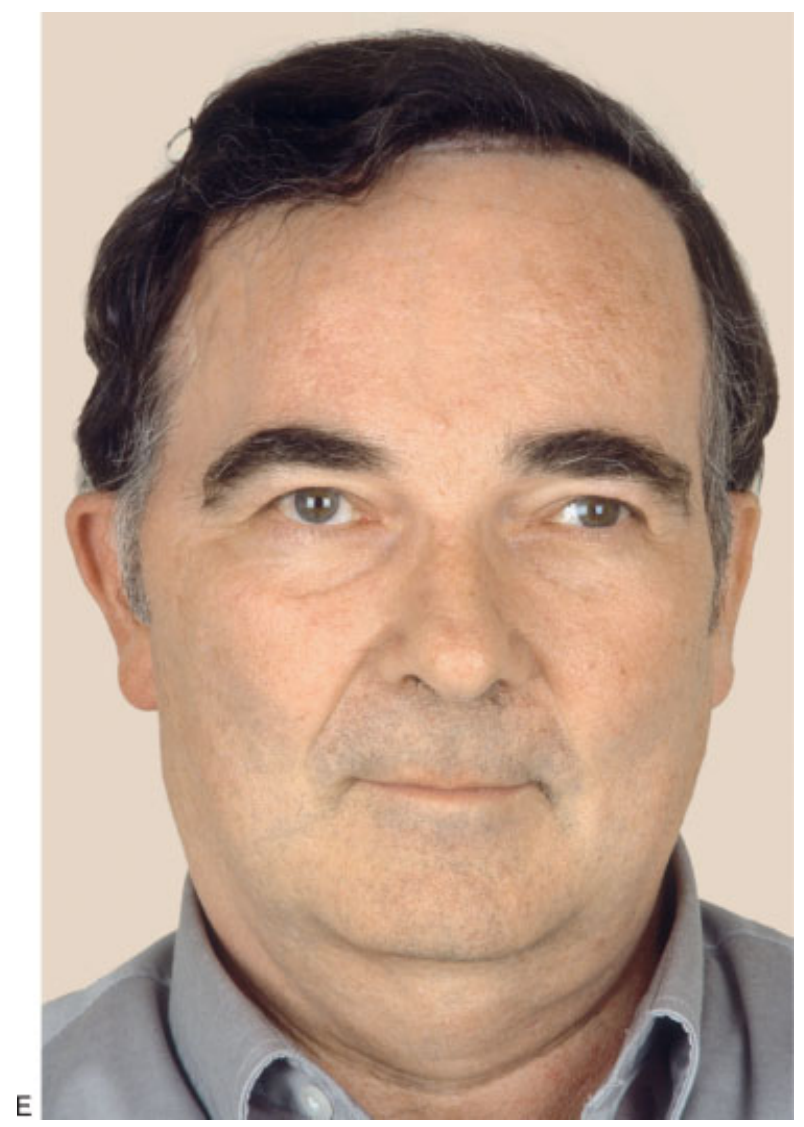

Figure 4 (Continued) (E) Postoperative view. Unfortunately, this patient underwent a fifth operation and the calcium-based bone cement was once again removed 2 years later because of infection and wound breakdown. (Reprinted with permission from Zins JE, Moreira-Gonzalez A, Papay FA. Use of calcium-based bone cements in the repair of large, full-thickness cranial defects: a caution. Plast Reconstr Surg 2007;120(5):1332-1342.)

Polymethylmethacrylate (PMMA) is an acrylicbased resin with broad applications. It may be prepared into a cement by mixing powdered methylmethacrylate polymer and liquid methylmethacrylate monomer, which polymerize during an exothermic reaction. PMMA is also available in block form. PMMA cement has been used for many years to secure orthopedic prosthetics and fill craniofacial defects. This polymer is rigid, biologically inert, and minimally reabsorbed. It is also relatively inexpensive and easy to obtain. ${ }^{24,33}$ Disadvantages of its use include lack of bioactivity, excessive heat produced with the polymerization reaction, lack of remodeling or replacement by new bone, and lifelong susceptibility to infection or extrusion.

Hard Tissue Replacement (HTR; Walter Lorenz Surgical, Inc., Jacksonville, FL) is a PMMA product that is prefabricated. HTR alloplastic implants are constructed based on high-resolution computed tomographic models. The custom-made implants come packaged for immediate use and can fit any number of complex craniofacial defects.
Advantages of the HTR include good strength, durability, surface osteoconductivity, biocompatibility, and some tissue ingrowth and revascularization. Additionally, there is no need for intraoperative mixing of reagents or waiting, leading to decreased operating room time. Disadvantages include the need to plan procedures in advance to allow time for prefabrication and lifelong risk of extrusion or infection. Infection rates in cranial reconstruction have been estimated at 5\%, with an increased risk when the nose or frontal sinus is involved. $^{24,33}$

Eppley and colleagues written extensively regarding the clinical use of PMMA and HTR in craniofacial reconstruction. ${ }^{34-37}$ In an animal study, they reported the HTR polymer to be biocompatible, with no evidence of infection, inflammatory reaction, or bone resorption around the implants. They also noted that the best osteoconductive effects were observed when the implants were exposed to bleeding cortical marrow as inlay grafts. Eppley also reviewed his experience in seven patients who had cranial reconstructions with prefabricated PMMA implants. ${ }^{36}$ In cases where the frontal sinus was in proximity to the implant, it was either cranialized and obliterated with a pericranial flap or obliterated with HA cement. Eppley reported excellent cosmetic results and no complications with a minimum of 1 year of follow-up. More recently, Eppley looked at the rigidity of the various forms of the PMMA implants, concluding that all forms of PMMA compare favorably with native bone in terms of measured impact resistance. ${ }^{37}$

Porous polyethylene or Medpor (Porex Surgical, College Park, GA) is a biocompatible, porous, highdensity polyethylene that has been used extensively in orbital reconstruction and facial contouring for the past 20 years. ${ }^{38}$ Available commercially in sheets, blocks, or preformed shapes, Medpor's high degree of porosity, with an average pore size of $100 \mu \mathrm{m}$ and pore volume of $\sim 50 \%$, promotes tissue ingrowth. The material is flexible enough to bend yet rigid enough to cut sharply. Medpor alloplastic implants may be placed subperiosteally and secured by closure of the periosteum and soft tissue over the implant. Alternatively, titanium or absorbable screw fixation may be used. Medpor products are also now available with titanium plates or meshes already incorporated to allow for easy screw fixation or increased structural support.

Yaremchuk reviewed his experience with 370 Medpor implants in 162 consecutive patients over 11 years. ${ }^{38}$ Implants were placed for a variety of acquired and congenital craniofacial deficits. All implants were placed in a subperiosteal pocket, and the majority secured using titanium screw fixation. Infections were reported in $3 \%$ of patients, and the overall reoperation rate was $10 \%$, including operative removal for facial recontouring and infection. No implant extrusions were reported. 
Cenzi and colleagues also reported a series of 285 Medpor implants placed in 187 patients over 7 years. ${ }^{39}$ Implants were used almost exclusively for craniofacial reconstruction and were placed as both inlays and onlays. Over a mean follow-up of 5 years, Cenzi et al reported an overall complication rate of $6.3 \%$, with implant exposure and infection being the most common. Risk factors for implant extrusion and infection included placement in the maxilla or ear, as well as placement in areas where soft tissue coverage was thin and/or scarred from irradiation or previous surgery.

Menderes et al reviewed their experience reconstructing craniofacial defects using 83 high density porous polyethylene implants in 71 patients over 7 years. ${ }^{40}$ Subperiosteal placement was performed in the vast majority of patients, and fixation was accomplished using titanium screws, absorbable screws and miniplates, or a stainless steel wire circulage. At a minimum of 1-year follow-up, the authors reported a nearly $10 \%$ reoperation rate for problems such as contouring irregularities and extrusion/infection. They concluded that the use of porous polyethylene is safe, easy, and effective and associated with low morbidity.

The rapidly expanding field of tissue engineering seeks to combine the stimulatory effects of bone growth factors, such as bone morphogenetic protein-2 and osteogenic protein-1 with bone substitute carriers to provide structural support during healing while delivering critical growth factors to the fracture site, promoting more rapid bone growth and healing. Bone mesenchymal cells have also been explored as a potential component in engineered bone substitutes for similar reasons. Potential delivery systems have included demineralized bone matrix, collagen composites, fibrin, calcium phosphate, polylactide, polylactide-co-glycolide, polylactidepolyethylene glycol, HA, dental plaster, titanium, and bioglass. ${ }^{41-53}$

Although the early history of bone substitution in craniofacial surgery gave emphasis to the physical properties of the material itself, the science of biomaterials and bone substitution is now increasingly focused on the biologic effects of the implant on the surrounding tissue, such as its ability to promote new bone growth. ${ }^{54} \mathrm{It}$ seems certain that the biologic interface between the alloplastic implant and host will guide the future of biomaterials to bring ever improving products to our patients.

\section{REFERENCES}

1. Urist MR, O'Conner BT, Burwell RG. Bone Graft, Derivatives and Substitutes. Cambridge: ButterworthHeinemann; 1994

2. Flati G, Di Stanislao C. Chirurgia nella preistoria. Parte I. Provincia Med Aquila 2004;2:8-11
3. Donati D, Zolezzi C, Tomba P, Viganò A. Bone grafting: historical and conceptual review, starting with an old manuscript by Vittorio Putti. Acta Orthop 2007;78:19-25

4. De Boer HH. The history of bone grafts. Clin Orthop Relat Res 1988;226:292-298

5. von Walter P. J Chir und Augen-Heilkunde 1821;2:571

6. Schlickewie W, Schlickewie C. The use of bone substitutes in the treatment of bone defects-the clinical view and history. Macromolecular Symposia 2007;253:10-23

7. Dressmann H. Ueber Knochenplombierung bei Hohlenformigen Defekten des Knochens. Beitr Klin Chir 1892;9:804810

8. LeGeros RZ. Properties of osteoconductive biomaterials: calcium phosphates. Clin Orthop Relat Res 2002;395: 81-98

9. Gibson IR, Bonfield W. Novel synthesis and characterization of an AB-type carbonate-substituted hydroxyapatite. J Biomed Mater Res 2002;59:697-708

10. FDA. Pre-market approval for Norian SRS Cement (PMA P970010). In: Services HaH, ed. 1998

11. Zins JE, Moreira-Gonzalez A, Parikh A, Arslan E, Bauer T, Siemionow M. Biomechanical and histologic evaluation of the Norian craniofacial repair system and Norian Craniofacial Repair System Fast Set Putty in the long-term reconstruction of full-thickness skull defects in a sheep model. Plast Reconstr Surg 2008;121:271e-282e

12. FDA. Bone Source HAC marketing approval. In: Services $\mathrm{HaH}$, ed. 2002

13. FDA. Mimix Bone Void Filler marketing approvalln: Services $\mathrm{HaH}$, ed. 2002

14. Goebel JA, Jacob A. Use of Mimix hydroxyapatite bone cement for difficult ossicular reconstruction. Otolaryngol Head Neck Surg 2005;132:727-734

15. Burstein FD, Williams JK, Hudgins R, et al. Hydroxyapatite cement in craniofacial reconstruction: experience in 150 patients. Plast Reconstr Surg 2006;118:484-489

16. Baker SB, Weinzweig J, Kirschner RE, Bartlett SP. Applications of a new carbonated calcium phosphate bone cement: early experience in pediatric and adult craniofacial reconstruction. Plast Reconstr Surg 2002;109:17891796

17. Gómez E, Martín M, Arias J, Carceller F. Clinical applications of Norian SRS (calcium phosphate cement) in craniofacial reconstruction in children: our experience at Hospital La Paz since 2001. J Oral Maxillofac Surg 2005;63:8-14

18. Verret DJ, Ducic Y, Oxford L, Smith J. Hydroxyapatite cement in craniofacial reconstruction. Otolaryngol Head Neck Surg 2005;133:897-899

19. Moreira-Gonzalez A, Jackson IT, Miyawaki T, Barakat K, DiNick V. Clinical outcome in cranioplasty: critical review in long-term follow-up. J Craniofac Surg 2003;14:144-153

20. Zins JE, Moreira-Gonzalez A, Papay FA. Use of calciumbased bone cements in the repair of large, full-thickness cranial defects: a caution. Plast Reconstr Surg 2007;120: 1332-1342

21. Losee JE, Karmacharya J, Gannon FH, et al. Reconstruction of the immature craniofacial skeleton with a carbonated calcium phosphate bone cement: interaction with bioresorbable mesh. J Craniofac Surg 2003;14:117-124

22. Miller L, Guerra AB, Bidros RS, Trahan C, Baratta R, Metzinger SE. A comparison of resistance to fracture among four commercially available forms of hydroxyapatite cement. Ann Plast Surg 2005;55:87-92; discussion 93 
23. Ducic Y. Titanium mesh and hydroxyapatite cement cranioplasty: a report of 20 cases. J Oral Maxillofac Surg 2002;60:272-276

24. Cho YR, Gosain AK. Biomaterials in craniofacial reconstruction. Clin Plast Surg 2002;31:377-385

25. Kitsugi T, Yamamuro T, Kokubo T. Bonding behavior of a glass-ceramic containing apatite and wollastonite in segmental replacement of the rabbit tibia under load-bearing conditions. J Bone Joint Surg Am 1989;71:264-272

26. Gosain A; KPlastic Surgery Educational Foundation DATA Committee. Bioactive glass for bone replacement in craniomaxillofacial reconstruction. Plast Reconstr Surg 2004;114: 590-593

27. Virolainen P, Heikkilä J, Yli-Urpo A, Vuorio E, Aro HT. Histomorphometric and molecular biologic comparison of bioactive glass granules and autogenous bone grafts in augmentation of bone defect healing. J Biomed Mater Res 1997;35:9-17

28. FDA. NovaBoneAR marketing approval. In: Services $\mathrm{HaH}$, ed. 2004

29. FDA. NovaBone Putty marketing approval. In: Services $\mathrm{HaH}$, ed. 2006

30. Cordioli G, Mazzocco C, Schepers E, Brugnolo E, Majzoub Z. Maxillary sinus floor augmentation using bioactive glass granules and autogenous bone with simultaneous implant placement. Clinical and histological findings. Clin Oral Implants Res 2001;12:270-278

31. Tadjoedin ES, de Lange GL, Lyaruu DM, Kuiper L, Burger $\mathrm{EH}$. High concentrations of bioactive glass material (BioGran) vs. autogenous bone for sinus floor elevation. Clin Oral Implants Res 2002;13:428-436

32. Duskova M, Smahel Z, Vohradnik M, et al. Bioactive glassceramics in facial skeleton contouring. Aesthetic Plast Surg 2002;26:274-283

33. Manson PN, Crawley WA, Hoopes JE. Frontal cranioplasty: risk factors and choice of cranial vault reconstructive material. Plast Reconstr Surg 1986;77:888-904

34. Eppley BL, Kilgo M, Coleman JJ III. Cranial reconstruction with computer-generated hard-tissue replacement patient-matched implants: indications, surgical technique, and long-term follow-up. Plast Reconstr Surg 2002;109: 864-871

35. Eppley BL, Sadove AM, German RZ. Evaluation of HTR polymer as a craniomaxillofacial graft material. Plast Reconstr Surg 1990;86:1085-1092

36. Eppley BL. Craniofacial reconstruction with computergenerated HTR patient-matched implants: use in primary bony tumor excision. J Craniofac Surg 2002;13:650-657

37. Eppley BL. Biomechanical testing of alloplastic PMMA cranioplasty materials. J Craniofac Surg 2005;16:140-143

38. Yaremchuk MJ. Facial skeletal reconstruction using porous polyethylene implants. Plast Reconstr Surg 2003;111:18181827

39. Cenzi R, Farina A, Zuccarino L, Carinci F. Clinical outcome of 285 Medpor grafts used for craniofacial reconstruction. J Craniofac Surg 2005;16:526-530

40. Menderes A, Baytekin C, Topcu A, Yilmaz M, Barutcu A. Craniofacial reconstruction with high-density porous polyethylene implants. J Craniofac Surg 2004;15:719-724
41. Chen B, Lin H, Zhao Y, et al. Activation of demineralized bone matrix by genetically engineered human bone morphogenetic protein-2 with a collagen binding domain derived from von Willebrand factor propolypeptide. J Biomed Mater Res A 2007;80:428-434

42. Clokie CM, Sándor GK. Reconstruction of 10 major mandibular defects using bioimplants containing BMP-7. J Can Dent Assoc 2008;74:67-72

43. Fu YC, Nie H, Ho ML, Wang CK, Wang CH. Optimized bone regeneration based on sustained release from threedimensional fibrous PLGA/HAp composite scaffolds loaded with BMP-2. Biotechnol Bioeng 2008;99:996-1006

44. Chung YI, Ahn KM, Jeon SH, Lee SY, Lee JH, Tae G. Enhanced bone regeneration with BMP-2 loaded functional nanoparticle-hydrogel complex. J Control Release 2007;121: 91-99

45. Hoshino M, Namikawa T, Kato M, Terai H, Taguchi S, Takaoka K. Repair of bone defects in revision hip arthroplasty by implantation of a new bone-inducing material comprised of recombinant human BMP-2, Beta-TCP powder, and a biodegradable polymer: an experimental study in dogs. J Orthop Res 2007;25:1042-1051

46. Murata M, Akazawa T, Tazaki J, et al. Blood permeability of a novel ceramic scaffold for bone morphogenetic protein-2. J Biomed Mater Res B Appl Biomater 2007;81:469-475

47. Liu HW, Chen $\mathrm{CH}$, Tsai CL, Lin IH, Hsiue GH. Heterobifunctional poly(ethylene glycol)-tethered bone morphogenetic protein-2-stimulated bone marrow mesenchymal stromal cell differentiation and osteogenesis. Tissue Eng 2007;13:1113-1124

48. Turhani D, Weissenböck M, Stein E, Wanschitz F, Ewers R. Exogenous recombinant human BMP-2 has little initial effects on human osteoblastic cells cultured on collagen type I coated/noncoated hydroxyapatite ceramic granules. J Oral Maxillofac Surg 2007;65:485-493

49. Okafuji N, Shimizu T, Watanabe T, et al. Tissue reaction to poly (lactic-co-glycolic acid) copolymer membrane in rhBMP used rabbit experimental mandibular reconstruction. Eur J Med Res 2006;11:394-396

50. Välimäki VV, Yrjans JJ, Vuorio EI, Aro HT. Molecular biological evaluation of bioactive glass microspheres and adjunct bone morphogenetic protein 2 gene transfer in the enhancement of new bone formation. Tissue Eng 2005;11: 387-394

51. Kim CS, Kim JI, Kim J, et al. Ectopic bone formation associated with recombinant human bone morphogenetic proteins-2 using absorbable collagen sponge and beta tricalcium phosphate as carriers. Biomaterials 2005;26: 2501-2507

52. Jensen TB, Overgaard S, Lind M, et al. Osteogenic protein-1 increases the fixation of implants grafted with morcellised bone allograft and ProOsteon bone substitute: an experimental study in dogs. J Bone Joint Surg Br 2007;89:121-126

53. Elsalanty ME, Por YC, Genecov DG, et al. Recombinant human BMP-2 enhances the effects of materials used for reconstruction of large cranial defects. J Oral Maxillofac Surg 2008;66:277-285

54. Anderson JM. The future of biomedical materials. J Mater Sci Mater Med 2006;17:1025-1028 